\title{
Associated Factors with the Child's Fully Immunized in the Tambacounda Health District (Senegal)
}

\author{
Khadim Niang1, Tidiane Gadiaga², Jean Augustin Tine³, Omar Bassoum ${ }^{3}$, Fatou Bintou Diongue ${ }^{3}$, \\ Amadou Ibra Diallo ${ }^{3}$, Adama Faye ${ }^{3}$, Ndiaye Papa' \\ ${ }^{1}$ Public Health Department, Gaston Berger University (UGB) of Saint-Louis, Saint-Louis, Senegal \\ ${ }^{2}$ Medical Officer of Tambacounda health district, Tambacounda Region, Senegal \\ ${ }^{3}$ Institut de Santé et Développement, Cheikh Anta Diop University, Dakar, Senegal \\ Email: khadimniang@outlook.com
}

How to cite this paper: Niang, K., Gadiaga, T., Tine, J.A., Bassoum, O., Diongue, F.B., Diallo, A.I., Faye, A. and Papa, N. (2020) Associated Factors with the Child's Fully Immunized in the Tambacounda Health District (Senegal). Open Journal of Epidemiology, 10, 167-178.

https://doi.org/10.4236/ojepi.2020.102015

Received: January 17, 2020

Accepted: May 6, 2020

Published: May 9, 2020

Copyright $\odot 2020$ by author(s) and Scientific Research Publishing Inc. This work is licensed under the Creative Commons Attribution-NonCommercial International License (CC BY-NC 4.0). http://creativecommons.org/licenses/by-nc/4.0/ (c) (i) (\$) Open Access

\begin{abstract}
To improve vaccination coverage among children under one year of age in the Tambacounda health district, a household survey was carried out among mothers or babysitters. The objective was to study the factors related to child's fully immunized in children aged 12 to 23 months. The cross-sectional, descriptive and analytical survey was carried out during the month of April 2019. A multistage cluster survey selected a sample of 657 mothers and babysitters. The data was collected using a questionnaire made from the World Health Organization reference guide. Data entry and analysis were done with Epi Info software and R. Among the women surveyed, biological mothers were the most representative (96.9\%). In the series, $74.1 \%$ had a good knowledge of the age for initiating vaccination, $78.2 \%$ knew the number of contacts. The vaccination record of the children was available in $92.2 \%$, and $71.0 \%$ of them had presented an adverse event. The proportion of children fully immunized was $41.0 \%$. Complete childhood vaccination was positively associated with income-generating activity in women $(0 \mathrm{R}=2.4)$ and the short distance $(<100 \mathrm{~m})$ between home and place of vaccination $(\mathrm{OR}=1.5)$. It was also improved by having a qualified health worker as a vaccinator $(\mathrm{OR}=1.4)$ satisfaction in relation to visit $(\mathrm{OR}=2.0)$, the advice given by the vaccinator $(\mathrm{OR}=1.7)$ and the fixing of the date of the next vaccination appointment $(\mathrm{OR}=2.5)$. The implementation of a good strategy for improving the quality of immunization services is an important element for strengthening immunization coverage in the Tambacounda health district.
\end{abstract}

\section{Keywords}

Vaccination, Child Health, Immunization Coverage, Senegal 


\section{Introduction}

Vaccination consists of immunizing a person against an infectious disease, generally by administering a vaccine [1]. It constitutes an essential component of the human right to health and an individual, collective and governmental responsibility.

Vaccines prevent the death of more than 2.5 million children each year [2]. Sheltered from vaccine-preventable diseases, vaccinated children can grow up in good condition and reach their full potential [2]. There is overwhelming evidence to demonstrate the benefits of immunization as one of the most effective and cost-effective health interventions known. Vaccination has allowed the eradication of smallpox, an achievement considered one of the greatest triumphs of humanity [3]. However, according to the WHO there are still 24 million children under the age of one year, almost $20 \%$ of children who are born each year, who cannot receive vaccines [2].

Senegal, to lead an effective and lasting fight against these vaccine-preventable diseases, has developed, like other countries, an immunization system integrated into primary health care called the Expanded Program on immunization (EPI) since 1979. Since then, several efforts have been made across the country with effective national vaccine coverage ranging from $59 \%$ in 2005 to $63 \%$ in 2011, then to $70 \%$ in 2013 , to reach $74 \%$ in 2014 [4] [5] [6] [7].

In 2018 , the proportion of children fully vaccinated was $82 \%$ at the national level. Even if the national target of $90 \%$ has not been reached for the country, it can be seen from 2005 to 2017 that vaccination coverage has improved for all antigens. Despite the multiple vaccination strategies implemented in the Tambacounda health district, the proportion of children fully vaccinated remains low. Administrative data from the Tambacounda health district established this coverage at $57 \%$ in 2018 while the national coverage was $76.6 \%$ [8]. In order to strengthen demand, this study seeks to identify the factors associated with the complete vaccination of children 12 to 23 months of age in the Tambacounda health district.

\section{Methodology}

\subsection{Study Framework}

The Tambacounda health district is located in the department and region of the same name. The Tambacounda region, located in the south-east of the country, is the largest region and only concentrates $5.5 \%$ of the population, making it the region with the lowest occupation of space.

The Tambacounda health district has an area of $11,416 \mathrm{~km}^{2}$ with an estimated population in 2018 of 274,697 inhabitants, and a natural growth rate of $2.7 \%$.

Fixed and advanced vaccination strategies are used to make it easier for the whole population to access vaccination in the interests of equity. All health facilities offer the routine vaccination service. During these different strategies, all the antigens in the program are delivered: 
- one dose of Bacillus Calmette-Guerin (BCG) vaccine,

- three doses of Oral poliovirus (OPV) vaccine,

- three doses of Pentavalent vaccine (Penta) include DTP (Diphteria, Tetanus and Pertussis) + Hepatitis B + Heamophilus influenzae b,

- three doses of Antipneumococcic (Pneumo) vaccine,

- two doses of Measle-Rubeola (MR) vaccine,

- one dose of Yellow fever (YF) vaccine.

There are six contacts vaccination, only MR2 is administered after the first birthday.

\subsection{Study Type}

The study was transversal, descriptive and analytical and took place from April 15 to $30,2019$.

\subsection{Study Population and Sampling Protocol}

The study population consisted of mothers and/or babysitters of children aged 12 to 23 months residing in the area of the Tambacounda health district.

Not included in the study were mothers or babysitters who expressed their refusal to participate, and those who were not available for the administration of the questionnaire.

The sample size was calculated using Schwartz's formula [9]. To maximize the sample size, the expected prevalence was set at 0.5 , with a $\mathrm{z}$ of 1.96 for an alpha risk of $5 \%$. The precision was set at $5 \%$. A cluster effect of 1.5 was considered giving a size of 577 , rounded to 600 . The sample was divided into 40 clusters of 15 mothers and babysitters each.

A multistage cluster sampling methodology was carried out for sampling. It was about selecting:

- First stage: A stratified survey was carried out at this level. It consisted first of all in distributing the 40 clusters at the level of the 23 health posts in the district and then identifying the districts and villages to be surveyed. An allocation proportional to the size of the population was made at this level. Thus, depending on the population served by the health post, one or more clusters were allocated to each area. Each cluster corresponded to a district or village, selected by systematic random survey.

- Second stage: The second degree of sampling allowed the selection of concessions to be investigated at the neighborhood and village level. At this level, a systematic random survey was used while respecting the proportions between the different villages. At the village level, all of the concessions were numbered. The sampling pool (interval between two household numbers) was calculated by dividing the total number of concessions in the village by the number of concessions to be surveyed. The first concession to be investigated was identified by drawing a number between the first concession and the number of the survey step, the supervisor drew up the list of concessions to 
be investigated for each village to be investigated.

- Third stage: This level of survey concerned the selection of mothers and babysitters within the concessions. All mothers/caregivers of the selected concession and fulfilling the selection criteria were surveyed. However, a mother and a babysitter could not be selected for the same child at the same time. Thus, for each household the mother had priority. In her absence the babysitter was selected. Only one person had to be selected in each concession included. When more than one person met the criteria for inclusion in the same household, a simple random survey was conducted by the interviewer. When the number of mothers/babysitters found in the household was equal to 1 , it was selected without drawing.

\subsection{Collection of Data}

The data was collected from a questionnaire developed for this purpose and inspired by the WHO reference manual [10].

The questionnaire was administered during an individual interview with mothers and/or caregivers of children aged 12 to 23 months. Data relating to the child's immunization status was collected from the vaccination card or from the history of vaccination reported by the mother or babysitters.

Apart from the child's immunization status, the interviewers also collected in households, information relating to socio-demographic characteristics, factors linked to the vaccination system, knowledge, attitudes and practices of mothers and babysitters on vaccination.

Thirty-eight interviewers, who had at least a medium secondary education and spoke the local language, were selected and trained to administer the questionnaire

\subsection{Data Entry and Analysis}

The data was entered in Epi info. A double entry was made to guarantee the quality of this entry.

The data was analyzed with the R 3.3.1 software [11]. Qualitative variables were described with absolute and relative frequencies and quantitative variables by mean and standard deviation.

Bivariate analysis was made to identify the factors associated with fully immunization. The odds ratio, surrounded by their $95 \%$ confidence interval (calculated by the Woolf method), made it possible to assess the existence of a statistical link and its strength.

\subsection{Ethical Considerations}

Taking part in this study was voluntary. It was done after free and informed consent. Investigators administered a comprehensive information form to the mother or caregiver. Confidentiality and anonymity were respected throughout the process. 


\section{Results}

At the end of the study, 657 people were surveyed, including 637 biological mothers, or $96.7 \%$.

The average age of the women surveyed was 31 years with a standard deviation of 7.6 years. The minimum age of these women was 15 and the maximum age of 60 . Women aged 25 - 34 were the most represented. The majority of women surveyed was not in school (62.7\%) and had no income-generating activity $(92.5 \%)$. Wives represented $98.3 \%$ of the sample (Table 1 ).

Table 1. Characteristics of the women surveyed and the child targeted $(n=657)$.

\begin{tabular}{|c|c|c|}
\hline Parameters & Absolute frequencies ( $n$ ) & Relatives frequencies (\%) \\
\hline \multicolumn{3}{|l|}{ Women's age groups } \\
\hline$[15-25$ years [ & 235 & 35.8 \\
\hline$[25-35$ years [ & 315 & 48.0 \\
\hline$[35-45$ years [ & 89 & 13.4 \\
\hline 45 years and over & 18 & 2.8 \\
\hline \multicolumn{3}{|l|}{ Place of residence } \\
\hline Rural & 354 & 53.9 \\
\hline Urban & 303 & 46.1 \\
\hline \multicolumn{3}{|c|}{ Marital status of the child's mother } \\
\hline Married & 646 & 98.3 \\
\hline Widow & 8 & 1.2 \\
\hline Divorced & 3 & 0.5 \\
\hline Single & 0 & 0.0 \\
\hline \multicolumn{3}{|l|}{ Incomegenerating activity } \\
\hline Yes & 49 & 7.5 \\
\hline No & 608 & 92.5 \\
\hline \multicolumn{3}{|l|}{ Education of the child's mother } \\
\hline Yes & 245 & 37.3 \\
\hline No & 412 & 62.7 \\
\hline \multicolumn{3}{|l|}{ Gender of child } \\
\hline Boy & 350 & 53.3 \\
\hline Girl & 307 & 46.7 \\
\hline \multicolumn{3}{|l|}{ Rank of child in siblings } \\
\hline 1 & 145 & 22.1 \\
\hline 2 & 132 & 20.1 \\
\hline 3 & 148 & 22.5 \\
\hline 4 & 67 & 10.2 \\
\hline 5 & 108 & 16.4 \\
\hline 6 and over & 57 & 8.6 \\
\hline
\end{tabular}




\section{Continued}

Knowledge of the number of contacts

$\begin{array}{lll}\text { Yes } & 515 & 78.4 \\ \text { No } & 142 & 21.6\end{array}$

Knowledge of the age of first contact

$\begin{array}{lll}\text { Yes } & 490 & 74.6 \\ \text { No } & 167 & 25.4\end{array}$

The children were 12 to 23 months old with an average age of 18 months and a standard deviation of 3.20. The median age was also 18 months and the sex ratio (boys/girls) was 1.14 . They were male in $53.3 \%$ of cases.

The women surveyed were among $74.6 \%$ of the women surveyed who were among the same as the age of first vaccine contact (from birth). The correct number of recommended vaccine contacts was cited by $78.4 \%$ of the women surveyed (Table 1).

No unvaccinated child was found during this investigation. The vaccination of the child was mainly done at the health posts $(56.0 \%)$, by a community worker in $54.3 \%$ of the cases.

Vaccine coverage by antigen was all greater than 55\%. However, adequate coverage (proportion of children fully immunised) was only $41.0 \%$. The Penta1/MR1 drop-out rate was $32.7 \%$ against $3.0 \%$ for the Penta1/Penta3 drop-out rate (Table 2).

$59.0 \%$ of the children were not fully vaccinated. The main reasons cited by mothers and caregivers for this incomplete vaccination was as follows:

- fear of adverse effects cited in $36.3 \%$ of cases;

- a trip outside the region in $24.7 \%$ of the cases;

- loss of the vaccination card in $12.4 \%$ of cases;

- the long distance between home and vaccination site in $8.5 \%$ of cases.

According to mothers and caregivers, an adverse post-immunisation manifestation was found in $71 \%$ of children. These were mainly fever (58.6\%), incessant crying $(27.8 \%)$, persistent local pain $(9.0 \%)$ and swelling at the injection site (6.8\%).

Child's fully immunization was positively associated with the presence of income-generating activity in the mother $(\mathrm{OR}=2.43)$, the high rank of the child in the siblings $(\mathrm{OR}=1.5)$, the short distance between the home and the place of vaccination $(\mathrm{OR}=1.5)$, the qualified profile of the vaccinator $(\mathrm{OR}=1.4)$.

Women's satisfaction with the quality of the vaccination service was also positively associated with child's fully immunization; with satisfaction with reception $(\mathrm{OR}=2.0)$, advice from the vaccinator $(\mathrm{OR}=1.7)$ and that of sharing the date of the next contact $(\mathrm{OR}=2.5)$ (Table 3$)$.

\section{Discussion}

In this study, the women surveyed were mainly the children's mothers (96.9\%). 
Table 2. Characteristics on childhood vaccination $(n=657)$.

\begin{tabular}{|c|c|c|}
\hline Parameters & Absolute frequencies (n) & Relatives frequencies (\%) \\
\hline \multicolumn{3}{|l|}{ Child's vaccination location } \\
\hline Health post & 368 & 56.0 \\
\hline Village (advanced strategy) & 199 & 30.3 \\
\hline Health center & 84 & 12.8 \\
\hline Hospital & 5 & 0.8 \\
\hline Private clinic & 1 & 0.1 \\
\hline \multicolumn{3}{|c|}{ Distance between home and place of vaccination } \\
\hline Less than $100 \mathrm{~m}$ & 288 & 43.9 \\
\hline At least $100 \mathrm{~m}$ & 369 & 56.1 \\
\hline \multicolumn{3}{|l|}{ Profile of the vaccinator } \\
\hline Doctor, nurse or midwife & 300 & 45.7 \\
\hline Community worker & 357 & 54.3 \\
\hline \multicolumn{3}{|c|}{ Systematic delivery of information by the vaccinator } \\
\hline Date of next contact & 571 & 86.9 \\
\hline Adverse effects of the vaccine administered & 539 & 82.0 \\
\hline Vaccine-protected diseases & 440 & 67.0 \\
\hline \multicolumn{3}{|l|}{ Availability of vaccination record } \\
\hline Yes & 606 & 92.2 \\
\hline No & 51 & 7.8 \\
\hline \multicolumn{3}{|l|}{ Vaccines received } \\
\hline BCG & 606 & 92.2 \\
\hline OPV 1 & 622 & 94.7 \\
\hline OPV 2 & 577 & 87.8 \\
\hline OPV 3 & 552 & 85.4 \\
\hline Penta 1 & 577 & 87.8 \\
\hline Penta 2 & 552 & 85.4 \\
\hline Penta 3 & 560 & 85.2 \\
\hline Antipneumococcic 1 (Pneumo 1) & 610 & 92.8 \\
\hline Antipneumococcic 2 (Pneumo 2) & 585 & 89.0 \\
\hline Antipneumococcic 3 (Pneumo 3) & 552 & 85.4 \\
\hline Yellow fever (YF) & 390 & 59.4 \\
\hline Measle-rubeola 1 (MR1) & 388 & 59.1 \\
\hline \multicolumn{3}{|l|}{ Differences between antigens of same contact } \\
\hline Penta1/OPV1 & 45 & 7.23 \\
\hline Penta2/OPV2 & 25 & 4.33 \\
\hline Penta3/OPV3 & 8 & 1.42 \\
\hline Penta1/Pneumo1 & 33 & 5.40 \\
\hline
\end{tabular}




\section{Continued}

$\begin{array}{ccc}\text { Penta2/Pneumo2 } & 33 & 5.64 \\ \text { Penta3/Pneumo3 } & 8 & 1.42 \\ \text { MR1/YF } & 2 & 0.51\end{array}$

Fully immunization of child

$\begin{array}{lll}\text { Yes } & 269 & 41.0 \\ \text { No } & 388 & 59.0\end{array}$

History of adverse reactions after childhood vaccination

$\begin{array}{lll}\text { Yes } & 466 & 71.0 \\ \text { No } & 191 & 29.0\end{array}$

Women's satisfaction with immunization services

$\begin{array}{ccc}\text { Reception } & 612 & 93.2 \\ \text { Waiting time } & 561 & 85.4 \\ \text { Vaccinator behavior } & 618 & 94.1 \\ \text { Advice on child health } & 578 & 88.0 \\ \text { Me date of the next contact } & 609 & 92.7\end{array}$

Legends: BCG: Bacillus Calmette-Guerin vaccine; OPV: Oral poliovirus vaccine; Penta: DTP (include Diphteria, Tetanus, Pertussis) + Hepatitis B + Heamophilus influenzae b; Pneumo: Antipneumococcic vaccine; MR: Measle-Rubeola vaccine; YF: Yellow fever vaccine.

Table 3. Factors associated with complete childhood vaccination $(n=657)$.

\begin{tabular}{ccc}
\hline \multicolumn{1}{c}{ Parameters } & Fully immunized n (\%) & OR [IC à 95\%] \\
$\begin{array}{c}\text { Place of residence } \\
\text { Rural }\end{array}$ & $124(41.0)$ & 1 \\
Urban & $145(41.0)$ & $0.99[0.7-1.4]$ \\
Marital status of the child's mother & & \\
Maried & $265(41.0)$ & $1.22[0.4-4.2]$ \\
Widow or divorced & $4(36.4)$ & 1 \\
Income generating activity & & 1 \\
No & $239(39.3)$ & $2.43[1.3-4.4]$ \\
Yes & $30(61.2)$ & 1 \\
Yes & & $0.99[0.7-1.4]$
\end{tabular}

Gender of child

$\begin{array}{ccc}\text { Boy } & 137(39.1) & 0.85[0.6-1.2] \\ \text { Girl } & 132(43.0) & 1\end{array}$

Rank of child in siblings

$\begin{array}{lll}\text { First } & 49(33.8) & 1\end{array}$

Others ranks

$220(43.0)$

$1.5[1.1-2.2]$ 


\section{Continued}

Knowledge of the number of contacts

$\begin{array}{lcc}\text { Yes } & 215(41.7) & 1 \\ \text { No } & 54(38.0) & 0.85[0.6-1.2]\end{array}$

Knowledge of the age of first contact

$\begin{array}{lcc}\text { Yes } & 198(40.4) & 1 \\ \text { No } & 71(42.5) & 1.1[0.8-1.5]\end{array}$

Distance between home and place of vaccination

$\begin{array}{ccc}\text { At least } 100 \mathrm{~m} & 135(36.6) & 1 \\ \text { Less than } 100 \mathrm{~m} & 134(46.5) & 1.5[1.1-2.0]\end{array}$

Availability of vaccination record

$\begin{array}{ccc}\text { Yes } & 249(39.2) & 1 \\ \text { No } & 20(41.1) & 1.08[0.6-1.9]\end{array}$

Profile of the vaccinator

$\begin{array}{ccc}\text { Community worker } & 134(37.5) & 1 \\ \text { Doctor, nurse or midwife } & 135(45.0) & 1.4[1.1-1.9]\end{array}$

History of adverse reactions after childhood vaccination

$\begin{array}{ccc}\text { Yes } & 193(41.4) & 1 \\ \text { No } & 76(39.8) & 0.93[0.6-1.3]\end{array}$

Women's satisfaction with reception

$\begin{array}{ccc}\text { Yes } & 257(42.0) & 2.0[1.1-3.9] \\ \text { No } & 12(26.7) & 1\end{array}$

Women's satisfaction with waiting time

$\begin{array}{ccc}\text { Yes } & 237(42.2) & 1.5[0.9-2.3] \\ \text { No } & 32(33.3) & 1\end{array}$

Women's satisfaction with vaccinator behavior

$\begin{array}{ccc}\text { Yes } & 257(41.6) & 1.6[0.8-3.2] \\ \text { No } & 12(30.8) & 1\end{array}$

Women's satisfaction with vaccinator advice on child health

$\begin{array}{ccc}\text { Yes } & 245(42.4) & 1.7[1.1-2.8] \\ \text { No } & 24(30.4) & 1\end{array}$

Women's satisfaction with sharing the date of the next contact

$\begin{array}{ccc}\text { Yes } & 258(42.4) & 2.5[1.2-4.9] \\ \text { No } & 11(23.0) & 1\end{array}$

In similar studies in Senegal, biological mothers were also more representative [12] [13] [14] with $91.4 \%, 93.1 \%$ and $93.3 \%$ respectively.

In our series, $53.8 \%$ of women resided in rural areas, which is in line with the estimates of the target for the health district establishing the rural population at 
$55.0 \%[15]$.

Among the women in this series, $92.5 \%$ were not engaged in any income-generating activity. Diop [14] had worked on a similar population in the Thilogne district where $92.4 \%$ were not engaged in income-generating activities. In the works of Tine to Popenguine [13] and Seck to Matam [16], these proportions were $79.0 \%$ and $89.4 \%$. It emerged from our study that there was a statistically significant link between vaccination and the presence of income-generating activities of the mother. Children of mothers with income-generating activities were 2.43 times more likely to be fully vaccinated. Seck [16] had also found the same association and linked it to the improvement in the availability of financial resources that women could use to get to health facilities.

$42.2 \%$ of the children were either 1 st or 2 nd of their siblings. This may be linked to the young age of the mothers surveyed. The child's rank in the siblings was statistically associated with the completeness of the vaccination.

The availability of the vaccination card could be a guarantee of complete vaccination. Indeed, Tine [13] had found that the availability of the vaccination card was a factor which increased the child's complete vaccination. In our study, the log was available in $89.5 \%$ of cases. However, it was not statistically linked to the complete vaccination of the child with an odds ratio of 0.93 [0.6 - 1.3].

Vaccination was carried out in $45.7 \%$ of the cases by qualified personnel in our study, and $79 \%$ in that of Tine [13]. This difference can be explained by the inequality in the distribution of qualified human resources between the two districts. In fact, the Popenguine health district is one of the smallest districts in Senegal with better accessibility of populations to health centers and posts in which qualified providers operate. Good accessibility to qualified providers is a favorable factor for complete vaccination, since children vaccinated with health workers with this profile are 1.5 times more likely to have full coverage.

In our series, $43.9 \%$ of the women surveyed walked less than $100 \mathrm{~m}$ to reach the immunization services. This indicates the proximity of the vaccination units. This good geographic accessibility was a factor favoring complete vaccination in our study with an odds ratio of 1.5 [1.1 - 2.0]. A similar result was found by Mezoe [17] in Cameroon by demonstrating that the greater the distance between the village and the health post, the less the child was likely to be fully vaccinated.

Vaccination coverage was above the national target (90\%) for only three antigens, namely BCG (92.2\%), OPV1 (94.7\%) and Pneumo1 (92.8\%). These performances were similar to those of Diop [14] and Tine [13]. Low coverage was noted for the YF and MR1 antigens with $59.4 \%$ and $59.1 \%$ respectively. The Penta1/Penta 3 dropout rates (2.94\%) were close to those found in the work of Seck [16] who found $8.6 \%$, and Diop [14] who estimated it at $9 \%$. These acceptable drop-out rates (less than 10\%) were the result of the search for irregular children by the system for stimulating irregulars and lost to follow-up in certain vaccination units. However, the search for the target of children 9 months and older was insufficient in this series because the dropout rate Penta1/MR1 was very high, at $32.7 \%$. 
The reasons most often cited by mothers and/or caregivers for non-vaccination were fear of adverse effects [36.3\%] and travelling outside the region [24.7\%]. Faye A [17], for his part, had found that the main reasons for leaving were lack of time $(40.3 \%)$, forgetting the appointment (33.2\%), loss of record card $(10.3 \%)$ and travel (7.7\%).

The women interviewed had good knowledge of the age of first contact (74.6\%) and the number of contacts for a complete vaccination (78.4\%). These proportions of good acquaintances are high compared to other studies in Senegal. Indeed, the proportion of mothers and babysitters knowing the number of contacts was only $24.2 \%$ with Diop [14] and $37.9 \%$ with Tine [13]. This difference can be linked to important communication initiatives at the community level implemented in the Tambacounda health district since 2015 to strengthen knowledge and improve the use of immunization services [15].

The quality of the vaccination service offer is an important element in improving adequate coverage at the level of the Tambacounda health district. In fact, our study has shown that the satisfaction of the mother or caregiver improves the completeness of the child's vaccination. The factors positively influencing the completeness of this vaccination were satisfaction with reception $(\mathrm{OR}=2.0)$, advice given by the vaccinator on the health of the child $(\mathrm{OR}=1.7)$ and sharing the date of the next appointment $(\mathrm{OR}=2.5)$.

\section{Conclusion}

Low adequate vaccination coverage is a reality in the Tambacounda health district. Improving the quality of the routine immunization service offer (geographic accessibility, reception, client-provider interaction, profile of qualified provider) is the main lever on which the district could rely to strengthen vaccine coverage.

\section{Conflicts of Interest}

The authors declare no conflicts of interest regarding the publication of this paper.

\section{References}

[1] Collège des universitaires de maladies infectieuses et tropicales (CMIT) (2004) E. Pilly-Maladies infectieuses et tropicales. 22ème ed.

[2] OMS/UNICEF/BM (2010) Vaccins et vaccination: La situation dans le monde. OMS, Genève.

[3] World Health Organization (WHO) (2013) Global Vaccine Action Plan 2011-2020. OMS, Genève, $148 \mathrm{p}$.

[4] Ndiaye, S. and Ayad, M. (2006) Enquête Démographique et de Santé au Sénégal 2005. Centre de Recherche pour le Développement Humain [Sénégal] et ORC Macro, Calverton.

[5] Agence Nationale de la Statistique et de la Démographie (ANSD) [Sénégal], et ICF International (2011) Enquête Démographique et de Santé à Indicateurs Multiples 
(EDS-MICS 2010-2011). ANSD et ICF International, Calverton.

[6] Agence Nationale de la Statistique et de la Démographie (ANSD) [Sénégal], et ICF International (2012) Enquête Démographique et de Santé Continue (EDS-Continue 2012-2013). ANSD et ICF International, Calverton.

[7] Agence Nationale de la Statistique et de la Démographie (ANSD) [Sénégal], et ICF International (2015) Sénégal: Enquête Démographique et de Santé Continue (EDS-Continue 2014). ANSD et ICF International, Rockville.

[8] Ministère de la santé et de l'action sociale, Direction de la prévention médicale [Sénégal] Bulletin d'Information de la Division de l'Immunisation. Vol. 5, No. 8.

[9] Ardilly, P. (2006) Les techniques de sondage. Editions TECHNIP, 675 p.

[10] Organisation mondiale de la santé (2018) Enquête de couverture vaccinale par sondage en grappes: Manuel de référence. OMS, Genève.

[11] R Core Team (2015) A Language and Environment for Statistical Computing. R Foundation for Statistical Computing, Vienna. http://www.r-project.org

[12] Badiane, O. (2007) Évaluation de la couverture vaccinale des enfants de 12 à 23 mois du district sanitaire de Ziguinchor (Sénégal). Mémoire DIU en Organisation et Management des Systèmes Publics de prévention vaccinale dans les Pays en Développement. Université de Cocody, Côte d'ivoire.

[13] Tine, Y. (2016) Étude des déterminants de la couverture vaccinale dans le district sanitaire de Popenguine, Sénégal. Mémoire épidémiologie. Université Cheikh Anta Diop de Dakar, ISED-Dakar.

[14] Diop, N.F. (2017) Etude des déterminants de l'utilisation de la série vaccinale complète des enfants âgés de 12 à 23 mois dans le district sanitaire de Thilogne, Matam (Sénégal). Mémoire épidémiologie. Université Cheikh Anta Diop de Dakar, ISED-Dakar.

[15] Équipe cadre du district sanitaire de Tambacounda (2018) Plan de travail annuel du DS de Tambacounda 2019. District sanitaire de Tambacounda.

[16] Seck, N. (2016) Etude des déterminants du statut vaccinal des enfants âgés de 12 à 23 mois dans le district sanitaire de Matam en 2016, Sénégal. Mémoire épidémiologie. Université Cheikh Anta Diop de Dakar, ISED-Dakar.

[17] Faye, A., Seck, I. and Dia, A.T. (2010) Facteurs d'abandon de la vaccination en milieu rural sénégalais. Médecin d Afrique Noire, 57, 137-141. 